\title{
A CONSCIÊNCIA DA INCERTEZA: OS DESAFIOS DE UMA POLÍTICA DE "TERRA-PÁTRIA"
}

\author{
THE AWARENESS OF UNCERTAINTY: THE CHALLENGES OF AN "EARTH- \\ HOMELAND" POLICY
}

\section{LA CONSCIENCIA DE LA INCERTIDUMBRE: LOS DESAFÍOS DE UNA POLÍTICA DE “TIERRA-PATRIA"}

\author{
Alfredo Pena-Vega \\ Professor-pesquisador, \\ Institut Interdisciplinaire d'Anthropologie du Contemporain-IIAC - \\ Centro Edgar Morin, EHESS/CNRS, Paris \\ Diretor cientifico do programa internacional Global Youth Climate Pact \\ penavega@ehess.fr
}

\begin{abstract}
A pandemia nos dá a oportunidade de sermos efetivamente seres "humanos", com respeito mútuo. Mas temos vivido em uma cultura que enfatiza a competição, a luta, ser melhor que o outro, vencer o outro. Portanto, com este contexto cultural, é difícil não estar na luta, deixar a colaboração aparecer. E para que a colaboração aconteça, eu tenho que confiar, tenho que ser honesto. (MATURANA, 2020).
\end{abstract}

Resumo: A tese central apresentada neste artigo não só permanece inquestionavelmente relevante, mas agora está sendo apresentada com ainda maior acuidade, dados os complexos eventos que estamos testemunhando: por que nosso futuro permanece imprevisível? Podemos prever alguma coisa nesta imprevisibilidade? Complexidade e incerteza estão no horizonte. Nossa consciência, portanto, está atrasada em relação aos eventos. Existe uma “crise"- no sentido médico de Hipócrates. Após os primeiros sintomas, torna-se claro que a sociedade global está doente - e a crise pode ser propícia à adoção de novos métodos. Mas há também o risco da tentação de egoísmos e soluções que transformam comunidades e espaços políticos em si mesmos. A crise da era ecológica é uma crise de nossa relação com a biosfera, e se não tomarmos consciência dos efeitos desta situação, corremos o risco de nos encaminharmos progressivamente para o suicídio coletivo. De que crise estamos falando? Da natureza, de nossa relação com a natureza e/ou com o meio ambiente, ou simplesmente de uma crise ecológica? "O que chamamos de crise ecológica [ou ambiental] é a consciência repentina de mais e mais incertezas" (LATOUR, 2010, p.14).

Palavras-chave: consciência; crise ambiental; sociedade global; outra economia; educação criativa.

\begin{abstract}
The main thesis presented in this article not only remains undeniably relevant but is now being presented more incisively, given the complex events we are witnessing: why does our future remain unpredictable? Can we predict anything in this unpredictability? Complexity and uncertainty are on the horizon. Therefore, our awareness lags behind events. There is a "crisis" - in the Hippocratic sense. After the first symptoms, it becomes clear that global society is sick, and the crisis could be conducive to the adoption of new methods. However, there is also the risk of the temptation of selfishness and solutions that turn communities and political spaces into themselves. The crisis of the ecological age is a crisis of our relationship with the biosphere. If we do not become aware of the effects of this situation, we risk heading progressively toward collective suicide. What crisis are we talking about? Of nature, of our relationship with nature and/or the environment, or simply an ecological crisis? "What we call an ecological [or environmental] crisis is the sudden awareness of more and more uncertainty" (LATOUR, 2010, p. 14).
\end{abstract}

Keywords: awareness; environmental crisis; global society; anothereconomy; creativeeducation.

\section{Resumen}

La tesis central presentada en este artículo no solo sigue siendo relevante de forma incuestionable, sino que ahora se está presentando con más acuidad todavía debido a los complejos eventos de los que estamos siendo testigos: ¿por qué nuestro futuro permanece imprevisible?, ¿podemos prever algo dentro de esta imprevisibilidad? Complejidad e incertidumbre están en el horizonte. Nuestra consciencia, por tanto, está atrasada con relación a los eventos. Existe una "crisis" -en el sentido médico de Hipócrates. Tras los primeros síntomas, queda claro que la sociedad global está enferma -y la crisis puede ser propicia a la adopción de nuevos métodos. Pero también existe el riesgo de caer en la tentación de egoísmos y soluciones que transforman comunidades y espacios políticos en sí mismos. La crisis de la era ecológica es una crisis de nuestra relación con la biosfera, y si no tomamos consciencia de los efectos de esta situación, corremos el riesgo de acercarnos progresivamente al suicidio colectivo. ¿De qué crisis estamos hablando? ¿De la naturaleza, de nuestra relación con la naturaleza y/o con el medio ambiente o simplemente de una crisis ecológica? "Eso a lo que llamamos crisis ecológica [o ambiental] es la consciencia repentina de más y más incertidumbres" (LATOUR, 2010, p.14).

Palabras clave: consciencia; crisis ambiental; sociedad global; otra economía; educación creativa.

Para citar - (ABNT NBR 6023:2018)

PENA-VEGA, Alfredo. A consciência da incerteza: os desafios de uma política de "Terra-Pátria". Eccos - Revista Científica, São Paulo, n. 57, p. 1-18, e20271, abr./jun. 2021. Disponível em: https://doi.org/10.5585/eccos.n57.20271. 


\title{
Dialogando com nossas contradições
}

Nossa era planetária está passando por uma das crises mais graves, e todos os ingredientes estão lá para colocar uma série de desafios futuros em perspectiva. Em novembro de 2017, enquanto os efeitos do aquecimento global continuavam a mostrar sinais de escalada (eventos excepcionais, aumento da temperatura, inundações, secas, etc.), quinze mil cientistas de 124 países publicaram um "aviso à humanidade" (MCKIBBEN, 2020). Foi um aviso inequívoco sobre o estado do nosso planeta: diminuição dos recursos de água potável, expansão das "zonas mortas" nos oceanos, diminuição catastrófica da biodiversidade, desmatamento em ritmo vertiginoso na Malásia, África Central, nas regiões amazônicas da Bolívia, Brasil, Colômbia, Peru e Guiana Francesa. Os cientistas nos advertem que "será tarde demais para mudar nosso rumo". Os legisladores não ouviram...

$\mathrm{O}$ advento do desastre pandêmico em dezembro de 2019 nos ensina que existem ligações entre a Covid-19 e a mudança climática. Os cientistas chamam nossa atenção para as políticas de redução de emissões de gases de efeito estufa (GHG) e medidas de saúde pública. De acordo com Klenert et al. (2020), “A crescente influência do homem sobre o ambiente natural ao longo dos séculos (Goudie, 2019) levou a desafios globais significativos na intersecção da saúde, dos quais o Covid-19 infelizmente não é uma das últimas manifestações”. Como argumentam Settele e Cortnie (2021), tanto a mudança climática quanto o surgimento de pandemias zoonóticas como a Covid-19 são o resultado da interferência humana nos ambientes naturais. O que está em jogo agora é nosso "destino terreno" ou "comunidade do destino" para parafrasear o filósofo Otto Baur, que Morin fez seu leitmotiv. O que está em jogo é uma nova relação com nossa ética da "Terra Pátria", na perspectiva de uma ecologia do futuro. Será que os formuladores de políticas vão ouvir desta vez?

Ademais, de acordo com os responsáveis políticos no fórum de Davos (2021),

\begin{abstract}
A Terra está aquecendo, as geleiras derretendo, os oceanos estão subindo e se enchendo de plástico. Estamos perdendo espécies, acumulando gases de efeito estufa e ficando sem tempo. Frente a estes fatos, o derrotismo é tentador. E ainda assim, há muitas razões para se regozijar. Uma palavra de ordem: "sustentável". Um imperativo que se aplica a todas as áreas da atividade humana - energia, alimentação, vestuário, viagens, cidades, etc.
\end{abstract}

Entretanto, quando o atual Davos (Fórum Econômico Mundial) se reuniu em 1974 pela primeira vez, o relatório do Clube de Roma, The Limits to Crowth (Os Limites do crescimento) havia sido publicado em 1972. De acordo com este relatório, a análise das causas e consequências a longo prazo do crescimento econômico global levaria a um futuro “insustentável". De fato, Dennis Meadows e seus coautores explicaram que os limites 
ecológicos planetários (em termos de uso de recursos e emissão de gases de efeito estufa) teriam consequências consideráveis no desenvolvimento global do planeta durante o século XXI (MEADOWS; MEADOWS; RANDERS, 2004). O capitalismo de Davos não levou em conta e não levará em conta as consequências dramáticas do crescimento exponencial em um mundo finito, escrito em preto e branco no relatório Meadows.

No entanto, aqui estamos, mais de 40 anos depois. O reducionismo econômico que o próprio homem ocidental gerou, em particular o dogma do crescimento, da produção industrial em massa de bens materiais, da atividade econômica ambientalmente inócua através da sociedade de consumo, não se enfraqueceu. "Qualquer um que acredita que o crescimento pode ser infinito em um mundo finito é um tolo ou um economista", escreveu o economista Kenneth Boulding. Mas, como Peccei (1983) nos lembrou, “O futuro não é mais... o que poderia ter sido se os homens soubessem como explorar sua inteligência e as possibilidades que lhes são abertas de forma mais eficaz. Mas ainda pode ser o que queremos que seja, se formos razoavelmente realistas". Esta visão reducionista é explicada pelo fato de que a relação com a terra, o meio ambiente e a natureza em geral permanece "[...] estritamente econômica, envolvendo apenas privilégios e sem obrigações morais e cívicas, ainda que toda evolução deva levar a uma mudança radical em nossa atitude nesta área” (AUDIER, 2020, p. 162).

Estamos em um momento decisivo em nossa maneira de ver e conceber nossa "TerraPátria”. As crises da era planetária estão convergindo, mas sua simultaneidade não é o resultado de uma coincidência infeliz, elas são todas o resultado de uma mesma e mais profunda crise. Esta multicrise é semelhante a todas as outras que todas as civilizações enfrentaram no decorrer da história humana. No entanto, há uma diferença, na medida em que esta é a primeira verdadeira crise planetária do nosso século. Antes de tudo, é uma crise de sentido: não sabemos mais como habitar a terra e não sabemos mais como viver com ela. Mesmo que estejamos muito otimistas quanto às capacidades tecnológicas futuras, à capacidade de reciclar ou salvar as matérias-primas que consumimos, ao controle da poluição ou ao nível dos recursos naturais, etc., etc., não é de se estranhar que esta ideia de colapso seja agora tão temida pelas pessoas (TAINTER, 1988) que teorizam uma "colapsologia".

Estamos diante de um dilema: será que tomamos consciência das convulsões do passado, será que a transformação do modo de vida de um país rico não é negociável ou, como George H. Bush declarou na Cúpula da Terra do Rio de Janeiro, de 1992, "o modo de vida americano não é negociável'? Entretanto, o futuro da humanidade está nos cofres dos mestres bilionários da tecnologia digital, que se esforçam para privatizar nosso futuro com a suposta missão de trabalhar cientificamente para o bem da humanidade, quando se trata simplesmente 
de expropriar nosso conhecimento e controlá-lo através de uma série de megaprojetos tecnológicos... todos apoiados pelo sonho da conquista do futuro. $\mathrm{O}$ que significa privatizar nosso futuro?

Não é mais o debate do início dos anos 2000 sobre os benefícios da globalização entre pessimistas e otimistas, mas uma discussão que hoje se concentra em qual modelo de civilização queremos: um modelo de abundância (híbrido) ou um modelo de sobriedade (neutralidade de carbono, sobriedade de consumo, etc.). A alternativa que estamos enfrentando coletivamente é esta: será o abismo ou será a transformação.

As perspectivas e a demanda por uma profunda transformação penetraram na mente das pessoas através de uma consciência coletiva das questões ecológicas, ambientais e sociais. Isto gera a necessidade de ir além de uma série de conceitos banalizados; notadamente o do modelo dominante: produtivismo, consumismo, dando-lhe novos significados. Isto deve nos permitir ver as possibilidades de surgimento de um "modelo alternativo" e torná-lo objetivo útil para um “convivialismo" (CAILLÉ, 2016) da atividade humana. André Gorz (2008, p. 25) explicou que “[...] o capitalismo atingiu um limite, tanto interno quanto externo, que ele é incapaz de superar e que o torna um sistema que sobrevive por subterfúgio à crise de suas categorias fundamentais: trabalho, valor e capital”. Indo além desta superação, Felix Guattari (2013, p. 18)afirmou que “[...] é necessário, portanto, enfrentar as gigantescas apostas de nosso tempo, reorientar radicalmente suas finalidades, passar de uma ecologia pastiça sobre a defesa do adquirido para uma ecologia futurista inteiramente mobilizada para a criação". Retornaremos a esta ideia da ecologia do futuro mais tarde.

Numa época em que nosso modelo de civilização acaba de passar por um de seus mais profundos desafios, este modelo dominante atual não é capaz de se reinventar radicalmente, pois os princípios econômicos enraizados em nossas sociedades só respondem aos interesses de curto prazo e à lógica de crescimento e acumulação de riqueza, caros aos liberais que são seguidores da "mão invisível". Além do mais, concomitantemente com seus princípios dominantes, os estilos de vida humanos (individual e coletivo) estão sendo profundamente perturbados como resultado de uma "pandemia social", devido aos efeitos existenciais do confinamento da Covid-19. As questões levantadas são: Quem sou eu? Quem somos nós? Em quem estamos nos tornando? Como fomos transformados?(entrevistas realizadas pelo jornal New York Time com seus leitores, em 2021).

Neste diálogo com nossas contradições, eu retomaria a ideia que Kostas Axelos nos propôs uma vez, de repensar o que nunca foi pensado de forma radical e pensar em direção ao 
próximo passo; ou seja, um passo na direção de uma ética de "terra-terra" para uma ecologia do futuro.

\section{Viver e lidar com a incerteza: uma "luz inalcançável”?}

Embora a incerteza faça parte da ciência e da pesquisa há muito tempo, antes do advento da crise pandêmica, testemunhamos uma espécie de repulsão das incertezas no uso e no raciocínio de certos fenômenos. Como sabemos, e em praticamente todos os campos, mais ou menos, "da Razão", parece que, fundada ou ilusória, a certeza prevalece sobre a aporia. O desafio de agora em diante será enfrentar as incertezas.

$\mathrm{Na}$ origem de todas estas reflexões estão questões sobre a natureza da incerteza. E esta observação: as incertezas estimulam a atenção, a vigilância, a curiosidade e a preocupação, que por sua vez estimulam o desenvolvimento de estratégias cognitivas, ou seja, modos de conhecimento através da incerteza, vagueza, aleatoriedade e acaso ${ }^{1}$.

Nossa hipótese central é que as dúvidas que surgiram da convulsão planetária da pandemia têm um escopo extremamente profundo, mas de uma profundidade que é ao mesmo tempo inesperada e preditiva. Inesperado, porque revela, por um lado, a necessidade de integrar em nosso modo de pensar a dúvida e o erro, que deve ser a condição sino quo non de uma pesquisa, de um exame e de uma reflexão. Por outro lado, o inesperado tem um atributo de anunciar catástrofes ecológicas e políticas, que são a ocasião para novas direções. Devemos assumir o problema da evolução do mundo como um todo a fim de tentar identificar os limites de um modelo dominante pós-crise e, se possível, evitar a sua reprodução.

Qual é o denominador comum na grande diversidade de respostas desenvolvidas frente às ameaças ecológicas, climáticas, sociais e políticas? É a incerteza, o imprevisível? Ou é dúvida, erro e incerteza no conhecimento, representação e modelagem de sistemas complexos de uma só vez?

Alguns acreditam que as ameaças estão recuando, outros que estão crescendo a um ritmo vertiginoso, outros que isso acabará sendo positivo, ou apocalíptico, ou mesmo que estas ameaças estão entre muitas outras que a humanidade deve superar, e ainda outros que este é o problema mais sério que ela já enfrentou. As ameaças são às vezes experimentadas em termos de perda econômica, injustiça ou riscos existenciais com efeitos irreversíveis. Assim,

\footnotetext{
${ }^{1}$ Dirigi o seminário "A incerteza e as suas apostas" (L’incertitude et ses enjeux) no EHESS entre 2005 e 2019. Este seminário baseou-se no princípio da transversalidade do conhecimento ao favorecer orientações científicas que abrangem vários campos da ciência: ciências humanas, ciências da vida, ciências do universo, ciências da terra, ciências do meio ambiente e ciências do clima. Nos últimos anos, procuramos enfatizar temas transdisciplinares: a natureza da incerteza na teoria evolutiva, crises, catástrofes, fenômenos ambientais, mudanças globais, eventos climáticos, sendo o fio condutor teórico os conceitos de complexidade e incerteza. Veja a revista Communications, Seuil, n. 95. Este seminário foi vítima de sua visão premonitória do desastre do vírus Covid-19 e suas incertezas.
} 
poderíamos compreender a importância dada às ameaças em termos do presente e do futuro (ORD, 2020).Nesta diversidade de pontos de vista, é necessário sublinhar a contribuição frequentemente controversa do sofisma, que torna a não ocorrência uma impossibilidade. Como diz Dupuy (2021, p. 40), “[...] um evento que nunca acontece deve ser considerado impossível”. A ilustração perfeita é o discurso dos pró-nuclearistas franceses que consideram um acidente nuclear impossível em seu país! Uma espécie de "negação" do alcance de uma crise. Entretanto, através desta diversidade de pensamento, emerge um postulado segundo o qual seria uma convicção moral ligada à própria possibilidade que a humanidade teria de perturbar os sistemas naturais de forma consistente. Poderíamos aderir em parte a este postulado, mas penso que, mais do que uma questão de moralidade, é a consciência de nossas incertezas que é difícil de aceitar. Devemos, portanto, viver e pensar com eles. A primeira incerteza é a da vida cotidiana: incerteza sobre o que vai acontecer no futuro. Apesar das dificuldades existenciais, isto não é uma má notícia. Outra incerteza, segundo Ord (2020, p.56), “[...] é a incerteza moral: incerteza sobre a natureza de nossos compromissos éticos". Entretanto, a necessidade de tornar a crise uma prioridade global não requer certeza.

Especificamente, do ponto de vista moral, há uma crescente consciência, embora às vezes parcial, dos perigos que ameaçam o ambiente natural de nossas sociedades. Além do que o reconhecimento, no final, das incertezas é o que caracterizaria a atual crise global. A busca de uma saída para os problemas de saúde e climáticos é concomitante em termos de desafios?

Cabe lembrar que as negociações sobre a mudança climática -ontem Paris (COP21),proximamente as negociações em Glasgow, novembro 2021 (COP26) - e o tsunami social da pandemia destacam a ideia imperativa do surgimento de outra "alternativa" como um processo de transformação em relação ao modelo dominante de desenvolvimento. A sociedade mundial está mergulhada em uma grande incerteza: sanitária (pandemias, zoonoses), econômica (crise generalizada), urbana (má vida, agressões), psicológica (ansiedade, medo do futuro) e moral (murchamento do senso de dever, corrupção). Mais do que uma coincidência, há realidades que não enganam. Além do desastre sanitário e econômico, é o conjunto do modelo dominante atual que é posto em questão por este "desastre" global. Talvez não seja coincidência que as teorias do colapso estejam tendo um certo sucesso.

Alguns meses antes da conferência mundial sobre mudança climática (COP26, novembro 2021, Glasgow), a mudança climática, longe de ser um desafio para o modelo atual, está, ao contrário, destacando seus limites e anunciando ameaças: ecológicas, sanitárias, sociais, políticas (democracia), cujas consequências a médio e longo prazo são incertas. "O destino do mundo é o de um confronto teórico - ou ideológico, se preferir - e o de um equilíbrio de 
poder"'(PASSET, 2001, p. 157).A complexidade do mundo nos perturba porque a compartimentação das ciências leva à enfermidade do pensamento: embora estejamos em uma "sociedade do conhecimento", sofremos de deficiências cognitivas e/ou continuamos a conceber a visão do mundo em uma lógica de "racionalidade cognitiva instrumental". Precisamos de um novo impulso para uma política da "Terra-Pátria" e/ou uma política da humanidade para salvaguardar o melhor da política de desenvolvimento e o melhor de cada civilização.

Os decisores políticos são como a ciência: compartimentados, dispersos, cada um tendendo a seu próprio jardim. Por que, nestas condições, o objetivo de problematizar outra alternativa tem tanta dificuldade em se impor na prática? Porque se depara com múltiplos interesses econômicos, financeiros e científicos, certamente. Mas também, talvez, por uma razão mais sutil e preocupante: a dificuldade de questionar uma visão paradigmática dominante de nosso sistema-mundo. As certezas que tendem a se impor em todos os lugares impedem assim um verdadeiro pensamento radical. Como podemos pensar hoje sobre a ideia de desafios relevantes?

Ademais, esta situação nos dá uma resposta diferente - ou prova - a tudo o que teorizamos nas últimas décadas. Esta é uma das principais novidades, que nos colocaria diante de um verdadeiro desafio epistemológico: é a ideia da "invasão epistêmica"(BALLANTYNE, 2015). De acordo com Nathan Ballantyne, a invasão epistêmica ocorre quando um cientista vai claramente além de seu campo de estudo e fala de um tópico sobre o qual lhe faltam dados ou conhecimentos para avaliar as provas e/ou dados. É verdade que nossas crenças se baseiam apenas parcialmente em uma base de provas relevantes. Até certo ponto, transgredir os limites do conhecimento exigiria um verdadeiro avanço epistêmico (MORIN, 2020). Sem querer extrapolar entre, por um lado, um acúmulo abundante de conhecimentos no campo do clima, dando mesmo origem a uma maior sensibilidade ecológica por uma parte da população e, por outro lado, um Covid-19, onde não dominamos todas as interações científicas, deixando em aberto o sentimento de uma ameaça nem sempre perceptível. Estamos em um nevoeiro. Será que nosso conhecimento destes fatos poderia nos levar a pensar de forma diferente a respeito de nossas crenças sobre nosso futuro?

O advento do coronavírus sem dúvida contribuiu para uma releitura de nossa visão existencial. Nossas certezas sobre a verdade científica se despedaçaram. A ciência ainda não tem a certeza de onde vem este coronavírus. É amplamente suspeito que seja o resultado da transmissão de animais selvagens para humanos - zoonoses. Certamente, sobre este argumento tivemos provas da origem deste vírus, mas também temos provas contrárias da validade desta 
tese. Sabemos com certeza, no entanto, que cerca de nove meses após a propagação deste coronavírus na cidade de Wuhan, 19,7 milhões de pessoas foram infectadas e quase 800 mil morreram no mundo inteiro, e há mais de 60 milhões de desempregados, incluindo um número significativo de jovens.

Numa época em que os cientistas estão lutando para impor seus conhecimentos, os princípios que apresentei esboçam o que seria uma narrativa verdadeira para apreender o imprevisível. Como sabemos, os eventos são muitas vezes imprevisíveis. A tragédia ecológica e humana de Chernobyl em 1986 (PENA-VEGA, 2016; PENA-VEGA; GRAPPE, 2021), bem como o triplo desastre de Fukushima no Japão, em 2011, foram acontecimentos imprevistos. Ninguém havia previsto um tal desastre nuclear no Japão. A segurança nuclear japonesa considerava que tal acidente era tecnologicamente impensável. Portanto, foi um evento imprevisto.

Finalmente, se voltarmos atrás na história de uma grande catástrofe, queremos esconder a ideia de que tudo o que era importante era imprevisto. Finalmente, quem poderia imaginar que, pela primeira vez na história da humanidade em escala planetária e global, "[...] encontramos algo [coronavírus] cujo poder é muito maior que o nosso e que consegue nos deter durante meses em nível planetário"(COCCIA, 2020). Então, aí está, três eventos que são invisíveis no momento e têm consequências imprevisíveis. Não sabemos o que é invisível hoje em dia. Pode não haver nada invisível, mas não é certo. Há sempre uma zona escura, algumas causas ocultas... Agora, no coração desta zona escura, e parafraseando Werner Heisenberg, há um princípio de incerteza; no centro do paradigma da incerteza, "[...]há o problema da insuficiência de lógica e a necessidade de uma lógica que integre o confronto dialético da contradição". A incerteza está, portanto, no âmago da lógica. "Há um princípio de incerteza e, como acabamos de discutir, há um princípio de incerteza no coração da lógica”(PENA-VEGA, 2018).

\section{Os desafios plurais da "Terra-Pátria"}

Aqui estamos, mais uma vez, confrontados com o grande paradoxo: tanto quanto a globalização - ou seja, a interdependência de todos os fenômenos planetários - é uma realidade, uma oportunidade e mesmo um risco, estes fenômenos também levam a uma globalização de ameaças: desequilíbrios na biosfera (ecológicos, climáticos), (bio)tecnológicos, sanitários, políticos, bem como fatores de exclusão e marginalização (econômicos, sociais, científicos, 
culturais), etc. Isto é um sinal, não apenas de um atraso da consciência sobre os fatos, mas também de um atraso dos fatos sobre a consciência.

A necessidade de uma (re)consciência deve nos levar "humanos"(como dizem os inuítes) a atribuir dois objetivos primordiais: por um lado, para garantir a sobrevivência da humanidade e, por outro lado, para tirá-la da barbárie em que ela ainda está imersa. Como atingir esses objetivos? Estes são os desafios que nos colocamos no projeto de reflexão sobre o conceito de "Terra-Pátria" por ocasião de um livro coletivo.

A fim de evitar a armadilha de um "realismo impossível", pedimos aos colaboradores deste livro que reflitam novamente, e de forma dialógica, sobre as relações conturbadas entre a certeza das ideias e a realidade incerta. É essencial lançar as bases para reformar e ampliar o pensamento (filosófico, político, ecológico), reunindo o que foi disperso e restaurando a complexidade dos problemas humanos na base deste novo conceito de "Terra-Pátria", no qual a utopia parece mais realista do que o pragmatismo de gerentes tranquilizadores, mas cegos.

Embora uma crise seja certamente a possibilidade de morte, ela também é a possibilidade de mudança. A transformação (metamorfose, mutação) que devemos empreender só será possível se admitirmos que as crises de hoje não podem ser resolvidas separadamente. Uma crise planetária só pode ser respondida por uma política da "Terra-Pátria". Esta não é uma fórmula ad hoc ou uma frase usada para iluminar um discurso, mas uma abordagem global que leva a um programa concreto e abrangente que visa a enfrentar os desafios de nosso tempo. " $\mathrm{O}$ problema do fim do mundo é o problema do fim da história (Francis Fukuyama): o fim em si não acaba; somos simplesmente apanhados em uma estranha imobilidade" (ZIZEK, 2020, p. 131).

Gostaria de retomar aqui uma ideia antiga, mas ainda atual de Günther Anders (2008), segundo a qual nossas reflexões acadêmicas sobre o que Toby Ord (2020)chama hoje de "riscos existenciais e o futuro da humanidade" devem passar à exigência de compreender a situação de urgência vital à qual a humanidade (civilização) está exposta. É uma questão de uma filosofia política que tem algum peso nos desafios da condição humana em ruptura com uma filosofia discursiva abstrata que ignora tudo da realidade dos desastres. Eu gostaria de fazer a seguinte pergunta: qual é a natureza da "terra-pátria”, e como esta natureza modifica a estratégia?

É uma questão de mudar nossa trajetória. Isto significa, antes de tudo, admitir, tomar consciência de que a superação do “impasse planetário”(GUATTARI, 2013, p. 33), no qual nos encontramos, requer a compreensão de que a humanidade e a biosfera são indissociáveis, o futuro de um e do outro é igualmente dependente de nossa "comunidade de destino terrestre"(MORIN; KERN, 1993, p. 213). 


\section{O desafio do pensamento}

Estamos testemunhando uma verdadeira revolução paradigmática, ou seja, uma ruptura na visão do mundo? Às vezes uma simples mudança, uma simples permutação, como a permutação entre a terra e o sol, é suficiente para derrubar efetivamente toda uma visão de mundo. Podemos dizer que, nas teorias científicas, há saltos ontológicos de um universo para outro, eles não se amontoam uns sobre os outros. Ao adotar um modelo crítico não reducionista, Morin se afasta de um realismo científico reducionista (MORIN, 2017).Ele prefere outra interpretação da ciência, em interconexões entre loops que são auto produtivos e autoorganizadores a um método de pensamento baseado em um duplo princípio de disjunção e redução, que ele chama de princípio de simplificação.

A partir do final dos anos setenta, o trabalho de Edgar Morin tem algo extraordinário, quase heroico (parafraseando Jean Marie Domenach), por sua vez, mitologia, filosofia, biologia, física, sistêmica, cibernética, etc., compõe a aventura científica de um pensamento, coloca-se em toda a encruzilhada da verdadeira modernidade. Como muitas vezes descrito, “[...] a aventura científica é uma aventura complexa na qual a implacabilidade empírica da observação, do questionamento e da experimentação finalmente trouxe à tona o que tinha sido perseguido por princípio: a complexidade” (MORIN, 1979, p.23).

Trata-se de "formular princípios de inteligibilidade complexa"; ou seja, o princípio da universalidade ("não há ciência, exceto a geral") deve ser associado a um princípio de inteligibilidade baseado no local e no singular. O princípio do reconhecimento da irreversibilidade do tempo físico (segundo princípio da termodinâmica) e do tempo biológico (ontogenia, filogenia, evolução) deve ser re-problematizado na perspectiva organizacional antropo-social. Morin propõe a intervenção da história em todas as descrições e explicações. Também, ele insistirá em três pontos que, em minha opinião, são paradigmaticamente inevitáveis: a ideia de que o conhecimento das partes se refere ao conhecimento do todo, que se refere ao conhecimento das partes (aqui estamos numa postura clara, nem holismo nem reducionismo); a inevitabilidade do problema de organização, do qual acabamos de varrer alguns princípios (intertroação, auto-organização, etc.); a inevitabilidade de um diálogo ordem/desordem/interação/organização em toda a busca de inteligibilidade em todo o mundo e a inescapabilidade de um diálogo de ordem/desordem/interação/organização em toda a busca de inteligibilidade nos fenômenos. 


\section{O desafio da democracia}

Devemos democratizar a democracia, o que significa, antes de tudo, sujeitar a globalização econômica à globalização política. Isto exige uma maior integração dos processos decisórios globais. Em termos concretos, isto significa fortalecer o peso das Nações Unidas nas relações internacionais e democratizar o funcionamento de seu Conselho de Segurança e sua relação com a Assembleia Geral e o Conselho Econômico e Social. Isto também pressupõe que uma "democracia cognitiva" viva seja trazida à vida, do nível local ao global, com base na capacidade dos cidadãos de se especializarem e reviverem esta ambição democrática original: o direito de cada indivíduo de cuidar de assuntos comuns. Em todos os continentes, este retorno dos cidadãos ao coração da deliberação política e da tomada de decisões está dando origem a práticas inovadoras que apontam o caminho para uma necessária "democratização da democracia”, uma condição para que as pessoas tomem de volta seus destinos em suas próprias mãos. Chegou o momento de transformar esta comunidade involuntária de riscos em uma comunidade de destino voluntária. Em outras palavras, chegou o momento de construir interdependência como um projeto, comprometendo-nos - como indivíduos, como membros de comunidades e nações distintas e como cidadãos do mundo - a reconhecer nossa responsabilidade e a agir, diretamente e através de Estados e Comunidades (sub e supranacionais), para identificar, defender e promover os valores e interesses comuns da humanidade.

\section{O desafio de outra economia}

Como a economia subjuga o ser humano e as finanças subjugam a economia, nossas vidas não receberam valor, mas preços. E, ainda assim, uma vida humana é precisamente aquela que não tem preço. Uma civilização plenamente humana só pode ser fundada sobre um humanismo integral, ou seja, a consideração constante do que é infinito no outro humano. Tratase de criar em nosso tempo, dentro de nossos vastos territórios e dentro de nossas numerosas populações, as condições para a renovação da amizade grega, aquele sentimento cívico, tanto político quanto ético, que manteve a unidade da cidade. A philia moderna é uma fraternidade. Em termos práticos, isto significa superar o anonimato em nossas sociedades que muitas vezes nos dispensa do respeito básico que devemos aos outros. Cidades, áreas suburbanas e áreas rurais não devem mais ser lugares de isolamento e segregação, mas lugares de cultura, intercâmbio, compartilhamento, igual dignidade e igual criatividade. Este objetivo e os valores 
que o fundamentam devem permear todas as políticas que são erroneamente consideradas setoriais, da habitação à saúde, do transporte à educação, do trabalho à paisagem e à arquitetura.

Os problemas de hoje se enraizaram na consciência dos seres humanos, e é na consciência dos seres humanos que devemos enraizar as políticas que os resolverão. Em termos concretos, isto significa manter unidos e tornar coerentes nossos pensamentos sobre democracia, economia, meio ambiente e relações sociais, não para moralizar o capitalismo, mas para teorizar a alternativa ao modelo dominante. Os modelos microeconômicos que estão na origem da crise financeira e econômica se baseiam na hipótese irrealista de uma racionalidade integralmente individualizada, isolada, desencarnada e instrumental. Devemos reexaminar a própria maneira pela qual usamos a razão, para torná-la capaz de compreender a multidimensionalidade das realidades e reconhecer a interação de interações e feedbacks. Devemos ir além dos maniqueísmos ideológicos e das mutilações tecnocráticas que reconhecem apenas realidades compartimentadas arbitrariamente, que são cegas ao que não pode ser quantificado, e que ignoram as complexidades humanas. Devemos abandonar a falsa racionalidade. As necessidades humanas nunca são apenas econômicas e técnicas, elas são sempre também emocionais, simbólicas e éticas.

A economia deve ser colocada a serviço do ser humano e do que, em nossas vidas, escapa à quantificação, a uma certa aptidão para a poesia da existência. Isto implica a regulamentação democrática das finanças e do comércio internacional. Em termos concretos, isto requer a criação de uma Organização Econômica Mundial que reúna as instituições de Bretton Woods e a OMC, e sua subordinação a uma Organização Mundial Social e Ambiental, colocada sob a égide das Nações Unidas, e que reúna a Organização Internacional do Trabalho e uma Organização Mundial do Meio Ambiente. Também exige regras claras, simples e robustas, incluindo a separação dos bancos de depósito dos bancos de investimento e a introdução de um imposto sobre transações financeiras para desencorajar a especulação.

Estamos entrando num período totalmente diferente da era passada de produção industrial em massa de itens materiais, onde as discussões sobre dinheiro, preços, retorno do investimento, leis de oferta e demanda, etc., não são as mesmas. Agora devemos pensar em termos de uma economia totalmente nova e sustentável, respeitadora de nossos recursos naturais. 


\section{O desafio social}

Acabamos esquecendo que uma sociedade é muito mais do que a soma dos indivíduos que a compõem. O desenvolvimento capitalista generalizou a mercantilização, erradicando o presente e o contra presente, o serviço gratuito, bens comuns não monetários, destruindo assim muitos tecidos de convivência. O desenvolvimento industrial impôs a lógica da máquina, a ditadura da produtividade a todo custo, do cronômetro e do curto prazo, em setores cada vez mais extensos de nossas vidas. A compartimentação do trabalho, das administrações e finalmente de nossas vidas levou a uma burocratização generalizada, à prevenção da iniciativa e da responsabilidade e finalmente à diminuição de nossa qualidade e poder de vida, o que é evidenciado pelo consumo desenfreado de drogas, ansiolíticos, antidepressivos, pílulas para dormir. O desenvolvimento urbano trouxe novas liberdades e atividades de lazer, mas também acelerou a atomização das sociedades, o que o enorme crescimento das redes de Internet não é suficiente para compensar.

Conectadas como nunca antes, nossas sociedades são também sociedades de solidão. As mudanças na família, para tomar apenas um exemplo, trouxeram novas liberdades, mas também novas restrições e fragilidades. O desafio civilizacional é repensar, em nosso próprio tempo, a articulação entre as liberdades individuais e a segurança coletiva. No decorrer de uma longa luta que começou no século XIX, os partidos e sindicatos de trabalhadores conseguiram tecer redes eficazes de solidariedade e obter proteção legítima. A ação histórica do socialismo e dos partidos de esquerda na França e na Europa havia conseguido criar um Estado de bem-estar ao qual a Liberação deu um grande impulso na França. Mas sob os golpes ideológicos e práticos do capitalismo, e também devido às profundas mudanças sociais e culturais, sua eficácia e legitimidade foram enfraquecidas, com uma administração fria e uma abordagem contábil estreita, prevalecendo demasiadas vezes sobre a atenção às necessidades de cada indivíduo, resultando em uma redução da solidariedade, quando, ao contrário, é necessário reinventá-la a fim de dar-lhe toda sua força. Há homens e mulheres de boa vontade em todo o país que estão prontos para dar seu tempo, força e calor à criação de novas solidariedades.

Cada um de nós está tentado a se retirar e disponível para ajudar um ao outro. Nossos poderes públicos, o Estado, as regiões, os municípios, devem criar as condições para o encontro e a sinergia da solidariedade e das energias fraternas. A fraternidade tornou-se a grande ausente do lema de nossa República. Devemos criar pontos de encontro que rompam o anonimato moderno, Casas de Fraternidade que reúnam instituições, associações e grupos de todo tipo que tenham em comum o serviço aos outros e a solidariedade entre os cidadãos. Podemos criar um 
serviço cívico de irmandade. Podemos reumanizar nossas grandes máquinas tecno-burocráticas e responder à mercantilização de tudo e de todos com uma rebelião ética, uma insurreição da vontade e um renascimento cívico. Podemos escolher cuidar uns dos outros e confiar nas reservas de generosidade que existem em cada um de nós e que só precisam ser ativadas por políticas públicas inspiradas por valores que são compartilhados muito além das fronteiras

partidárias, como atestam muitas das iniciativas de nossos concidadãos no terreno. É assim que vamos reconectar o que a luta de todos contra todos desatou e tornar possível esta aspiração universal à auto invenção e ao domínio de cada pessoa sobre sua própria vida.

\section{O desafio ecológico}

Neste desafio, trata-se de criar uma ecologia integral. Isto não se justifica apenas pelos limites da natureza, pelas estreitas inter-relações entre territórios e pelas mudanças significativas nos parâmetros que sustentam a vida na Terra. Mas também porque fomos sujeitos a uma visão do mundo (socioeconômica) dominante que impôs a sua própria forma particular de ver o mundo, com indicadores (quantitativos) e metodologias (competitivas) que favoreceram a acumulação injusta de riqueza por poucos, a fragilidade social de muitos e a depredação dos recursos naturais. Esta era a lógica da ordem de uma governabilidade global que deveria ser inseparável de uma nova ordem econômica global. A dívida ecológica que os países do Norte devem aos países do Sul é muito maior do que a dívida externa que os países do Sul devem aos países do Norte. Para resolver o problema da dívida do Sul, propomos a sua abolição pura e simples e a sua substituição pelo investimento ecológico dos países do Sul. A ecologia política não pode ser isolada. Pode e deve estar enraizada nos princípios das políticas emancipatórias que animaram a nossa história republicana, socialista e comunista, e que irrigaram a consciência cívica do povo de esquerda e progressista. Assim, a ecologia integral poderia acelerar o advento de uma grande política da "Terra-Pátria" e do "bem comum".

Nos últimos anos, a consciência coletiva tem defendido a qualidade de vida. Passar de quantitativo para qualitativo é uma forma de defesa da natureza e do ambiente e, ao mesmo tempo, uma defesa da qualidade humana. Precisamos de uma política explícita que nos permita comunicar, que alargue as ações dispersas; procurar uma política da "Terra-Pátria" que vise a melhorar a comunicação, o diálogo da nossa comunidade terrestre; por outras palavras, unir e ligar a comunidade. A conservação da natureza e a proteção do tesouro dos recursos sociais devem ser combinadas com a atual forma de pensar. 
A barbárie não acaba com o capitalismo. Temos de ver esta complexidade. É verdade que existe uma conjunção e uma divergência de políticas e é óbvio que a política é confrontada com a realidade; no entanto, não se trata de abandonar a causa, mas sim de reestimular uma revolução cognitiva.

\section{O desafio da educação criativa}

A educação criativa é a base de uma "Terra-Pátria". São nossos filhos que forjarão a Terra como uma pátria neste século de cidadania. É a eles que devemos dar o conhecimento, o know-how e as chaves para entender a complexidade do mundo. Nossa missão coletiva foi declarada por Jean-Jacques Rousseau no Emile: "Eu quero ensiná-los a viver". Devemos dar a nossos filhos os meios para enfrentar os problemas fundamentais e globais que são os problemas de cada indivíduo, de cada sociedade e de toda a humanidade. Estes problemas estão hoje desintegrados em e por disciplinas que são muito compartimentadas. É necessária uma reforma da universidade, para torná-la transdisciplinar. Mas na frente da cadeia educacional, a reforma dos cuidados e educação da primeira infância é igualmente necessária. Os resultados brilhantes obtidos, por exemplo, em um país como a Finlândia nos mostram a estreita ligação entre o bemestar na escola e o desempenho escolar. Como a desconfiança que rege nossas sociedades está enraizada na consciência humana desde a mais tenra idade, é na consciência humana que a educação em autoconfiança e confiança nos outros deve se enraizar desde a mais tenra idade.

\section{O desafio da política global: rumo à interdependência global}

Europa, América Latina, África, etc., não vivem no vácuo ou em um mundo imóvel. A situação da França, por exemplo, pode influenciar o curso do mundo, bem como ser afetada por ele. Mas a problemática relação que foi estabelecida entre o local e o global, com esta impressão desencorajadora de não ter mais controle sobre a desordem das coisas, é acompanhada por uma dúvida compreensível sobre a capacidade da França de promover o surgimento de uma nova política civilizatória global. No entanto, lemos em algum lugar que foi na França que estas palavras foram pronunciadas pela primeira vez: "Todos os homens nascem e permanecem livres e iguais em direito”. Lemos em algum lugar que esta Revolução sacudiu o resto do mundo com uma espécie de onda de choque universal. Lembramos que houve um tempo em que Saint-Just podia exclamar que "a França vota a liberdade do mundo". Esta parte de nossa história pode nos inspirar novamente, sem arrogância ou ingenuidade, mas a partir desta simples observação: o imperialismo do mercado e a lei do mais forte são impróprios para uma política civilizatória. 
Portanto, vamos fazer, em nosso nível para começar, a escolha de uma política exemplar que terá um impacto europeu e internacional. Comecemos por aplicar em nossas próprias latitudes o que recomendamos para o mundo e que muitos outros compartilham. Resumindo, vamos alinhar nossas ações com nossas palavras a fim de construir outra maneira de viver juntos que concilie o que há muito tempo tem sido oposto por uma cultura antiquada responsável por nossas barbaridades modernas.

Enquanto a era planetária atravessa uma grande crise (ou melhor, uma série de crises concomitantes: sanitária, climática, social, econômica, energética, alimentar, ética...), o futuro nunca pareceu tão incerto. Por toda parte, em tudo, as incertezas aumentaram. Entramos num momento de incerteza... A maioria dos governos enfrenta problemas de tal complexidade que sua capacidade de compreendê-los, de dominá-los e, a fortiori, de "resolvê-los", está seriamente comprometida. Para os decisores políticos, esta complexidade torna cada vez mais difícil desenvolver soluções simples e aceitáveis para todos, porque perdemos a evolução linear, o futuro programado e encoraja o questionamento. E para citar, como um "caso típico de governança complexa", o preocupante ressurgimento de novas doenças na América Latina e no Caribe, África. A propagação desta infecção viral pode ser explicada por uma combinação de múltiplos fatores de áreas, escalas e prazos muito diferentes: desmatamento, urbanização rápida, infraestrutura sanitária inadequada, o fenômeno climático El Niño/Niña...

Temos apenas uma compreensão limitada das transformações que ocorrem em nossa era planetária, e que "compreender um padrão complexo é tão complexo quanto o próprio padrão". Assim, encontramo-nos em um mundo que parece incerto e preocupante, em evolução, progressão, crise e perigo. $\mathrm{O}$ reconhecimento desta complexidade pode, entretanto, ser frutífero como fonte de outras formas de pensamento e ação. Como Edgar Morin escreve em Une politique de civilisation, “[...] hoje, o improvável, a crise, a catástrofe e a salvação caminham juntos, segurando-se um ao outro pelo braço” (MORIN; NAIR, 1997).

\section{Referências}

ANDERS, G. Hiroshima est partout. Paris: Éditions du Seuil, 2008. 519 p.

AUDIER, S.La cité écologique. Pour une éco-république. Paris: La Découverte, 2020. 747 p.

BALLANTYNE, N. The significance of unpossessed evidence. The Philosophical Quarterly, Oxford, v. 65, n. 260, p. 315-335, 2015.

CAILLÉ, A. Eléments d'une politique convivialiste. Lormont: Le Bord de l'Eau, 2016. 210 p. 
COCCIA, E. La terre peut se débarrer de nous avec la plus petite de ses créatures. Le Monde, Paris, 4 abr. 2020.

DAVOS. World Economic Forum. Davos, 2021. Disponível em: https://www.weforum.org. Acessoem: 13 maio 2021.

DUPUY, J.P. La catastrophe ou la vie. Pensées par temps de pandémie. Paris: Éditions du Seuil, 2021. $261 \mathrm{p}$.

GORZ, A. Ecologica. Paris: Galilée, 2008.

GOUDIE, S. A. Humain Impact on the Natural Environment. Pass, Present and Future. Oxford: Wiley Blackwell, 2019. 457 p.

GUATTARI, F.Qu'est-ce que l'Ecosophie?Paris: Editions Lignes poches, 2013. 586 p.

KLENERT, D.; FUNKE, F.; MATTAUCH, L.; O'CALLAGHAN, B. Five Lessons fromCOVID-19 for Advancing Climate Change Mitigation. Environmental and Resource Economics, n. 76, p. 751-778, 2020.

LATOUR, B. Remettre les non-humanis au cœur de la politique (entretien).Revue critique d'écologie politique, n. 34, 13 mars. 2010.

MATURANA, Humberto. Entrevista com Humberto Maturana: "La Epidemia nos da una oportunidad de ser efectivamente humanos".[Entrevista cedida a] Macarena Pizarro.CNN Chile, 1 may 2020. Disponível em: https://www.cnnchile.com/lodijeronencnn/entrevista-conhumberto-maturana-la-pandemia-nos-da-una-oportunidad-de-ser-efectivamentehumanos_20200501/. Acesso em: 13 maio 2021.

MCKIBBEN, B.Humanicide ou la fin d'un règne. Quand l'avenir de l'homme a-t-il basculé? Paris: Massot éditions, 2020. 325 p.

MEADOWS, D.; MEADOWS, D.; RANDERS, J. Les limites à la croissance. The 30- Year Update. Paris: Edition Rue de l'Échiquier, 2004. 394 p.

MORIN, E. Connaissance, ignorance, mystère. Paris: Fayard, 2017. 175 p.

MORIN, E. Changeons de voie. Les leçons du coronavirus. Paris: Denoël, 2020. 160 p.

MORIN, A. Le paradigme perdu: la nature humaine.Paris: Éditions duSeuil, 1979. (coll. Points Essais, n. 109). 240 p.

MORIN, E.; KERN B.Terre-Patrie. Paris: Éditions du Seuil, 1993. 217 p.

MORIN, E.; NAIR, S. Une politique de civilisation. Paris: Arléa, 1997. 250 p.

ORD, T. The Precipice. Existential Riskan the Future of Humanity. Londres: Bloomsbury Publishing, 2020. 468 p.

PASSET, R. Eloge du mondialisme par un “anti” présumé. Paris, Fayard, 2001. 167 p. 
PECCEI, A. Agenda for the End of the century. In: CONFERENCE BOGOTA. Development in a World of Peace. Bogota: Club of Rome, 1983.

PENA-VEGA, A. Dialoguer avec les incertitudes. Quand le doute est une chose sûre et les connaissaces. Gazeta de antropologia, Jaén, España, v. 33, n. 2, 2018. Disponível em: http://www.gazeta-antropologia.es/?p=5010. Acesso em: 19 ago. 2020.

PENA-VEGA, A. Tchernobyl, Catastrophe écologique, Tragédie humaine. Mémoire et Récit. Médis, Nova-Aquitânia: Editions Atlantique, 2016.

PENA-VEGA, A.;GRAPPE, M. Rêves de femmes de Tchernobyl. Revue Communication, Le Seuil, n. 103, 2021.

SETTELE, S.; CORTNIE, S. Lives or Livelihoods? Perceived Tradeoffs and Policy Demand. April 25, 2021. Disponível em: https://papers.ssrn.com/sol3/papers.cfm?abstract_id=3589891. Acesso em: 13 maio 2021.

TAINTER, J. The Collaphe of Complex Societies. Cambridge: Cambridge University Press, 1988. $250 \mathrm{p}$.

ZIZEK, S.Dans la tempête virale. Paris: Actes Sud, 2020. 155 p. 